\title{
Chromosomal phylogeny of the Drosophila fasciola species subgroup revisited (Diptera, Drosophilidae)
}

\author{
Nilda Maria Diniz ${ }^{1}$ and Fabio Melo Sene ${ }^{2}$ \\ ${ }^{1}$ Universidade de Brasília, Departamento de Genética e Morfologia, Brasília, DF, Brazil. \\ ${ }^{2}$ Universidade de São Paulo, Faculdade de Medicina de Ribeirão Preto, Departamento de Genética, \\ Ribeirão Preto, SP, Brazil.
}

\begin{abstract}
The analysis of polytene chromosomes in 26 strains of seven species in the Drosophila fasciola subgroup, from several locations in Brazil, in addition to strains of two species belonging to the Drosophila mulleri subgroup ( $D$. aldrichi and $D$. mulleri), enabled us to determine that the $3 c$ inversion found in the latter species differ in one of its break points from that present in the species of the fasciola subgroup. Therefore, a change in the mulleri complex denomination from inversion $3 c$ to inversion $3 u$ is proposed. Accordingly, the fasciola subgroup is no longer a lesser phylogenetic part within the mulleri subgroup. Rather, it is directly related to the likely ancestor of the repleta group, called Primitive I. This information removes the main obstacle to considering the Drosophila fasciola subgroup as an ancestral group within the Drosophila repleta species group, according to the hypothesis of Throckmorton. Our data also support the conclusion that $D$. onca and $D$. carolinae are closely related species based on one new inversion in chromosome $4\left(4 f^{2}\right)$, in both species. $D$. fascioloides and $D$. ellisoni also form a pair of sister species based on the presence of fusions of chromosomes $2-4$ and 3-5. D. rosinae is related only to the likely ancestor of the fasciola subgroup, where the $3 \mathrm{c}$ inversion was fixed.
\end{abstract}

Key words: Drosophila, chromosome phylogeny, repleta group, fasciola subgroup, chromosome inversions.

Received: March 28, 2003; Accepted: October 13, 2004.

\section{Introduction}

The repleta group of the genus Drosophila is endemic to the Americas. This group comprises more than 95 nominal species (Sturtevant, 1942; Vilela, 1983; Rafael and Arcos, 1989; Vilela and Bächli , 1990; Tidon-Sklorz and Sene, 1995a b, 2001; Bächli and Vilela, 2002), and is divided into six subgroups: fasciola, hydei, inca, mercatorum, mulleri and repleta.

Their species are widely distributed in the New World and mostly found in semiarid regions with open vegetation (Pavan, 1959; Sene et al., 1980; Vilela, 1983; Vilela et al., 1983; Tidon-Sklorz and Sene, 1995c; Tidon-Sklorz et al., 1994). The species in the hydei, mercatorum and repleta subgroups are mostly generalists, while those in the mulleri and inca subgroups use cacti as breeding sites (Pereira et al., 1983; Rafael and Arcos, 1989).

The fasciola subgroup comprises an assemblage of 21 nominal species (Wasserman, 1962a; Vilela, 1983; Vilela and Bächli, 1990; Bächli and Vilela, 2002), which inhabit

Send correspondence to Fabio Melo Sene. Faculdade de Medicina de Ribeirão Preto, Departamento de Genética, 14049-900 Ribeirão Preto, SP, Brazil. E-mail famesene@usp.br. mostly forests. They are associated with various substrates: for instance, $D$. fulvalineata was collected on fungi (Patterson and Wheeler, 1942); D. fasciola emerged from flowers and fruits such as Aphelandra micans (Acanthaceae), Erythrina berteroana (Fabaceae), Heliconia latispatha (Musaceae) and aroid (Araceae) (Pipkin et al., 1966). In forest environments, besides these substrates, these flies use epiphytic cacti (Rhypsalis sp.) as breeding sites (Sene et al., 1977, Morais et al., 1995). Moreover, in open vegetation, $D$. rosinae emerged from columnar cacti (Cereus sp.) (Wasserman, 1962a; Pereira et al., 1983; Tidon-Sklorz and Sene, 1995c). Apparently, the morphology of the testicles and of the seminal receptacle of the species in this subgroup is intermediate between that in the mulleri and repleta subgroups (Wasserman, 1962a).

The origin and adaptive radiation of the cactophilic species in the repleta group probably occurred in the Oligocene and Miocene (Throckmorton, 1975, 1982). This group is likely to have originated in the transition zone between the Nearctic and Neotropical biogeographic regions in Mexico (Wasserman, 1954).

Cytologically, the ancestral species of all fasciola subgroup would have evolved from the Primitive I, a hypo- 
thetical sequence of polytene chromosomal bands, suggested by Wharton (1942), that differs from the standard arrangement of the Drosophila repleta by the presence of the Xabc;2ab;3b inversions, and by the fixation of the $2 \mathrm{o}^{3}$, $2 \mathrm{e}^{3}$ and $21^{3}$ inversions. Accordingly, the basic chromosomal composition of the subgroup would be the Primitive VII (Xabc; 2abo $\mathrm{e}^{3} 1^{3}$; 3b; Wasserman 1960, 1962a, 1992).

According to Wasserman (1982), the existence of the $3 \mathrm{c}$ inversion in species of the mulleri complex (included in the mulleri subgroup) and of the fasciola subgroup sustains the hypothesis of a common ancestry, with the fasciola subgroup stemming from the mulleri subgroup. The fact that the species of the fasciola subgroup are forest dwellers could be an indicator of reinvasion of the forests by desertadapted species.

Throckmorton (1982), and in earlier works (Throckmorton 1962, 1975), discusses the problem of the origin of the repleta group and states: "whether the ancestor of the repleta group itself was a forest species which "became" a "repleta", began diversifying in the forest, and subsequently moved into arid habitats, or whether it first moved into arid habitats and became a repleta there, is difficult to determine. Its closest relatives, the castanea, canalinea, dreyfusi and mesophragmatica groups, are forest forms, for the most part, and apparently primitive members of the repleta group that are at least facultative forest forms breeding in fallen fruit. Parsimoniously, this permits the inference that the founder of the repleta group was a forest form, not necessarily of the wet forest, which "became" a repleta while still associated with forest habitats. At the present time, and on anatomical grounds especially, the major separation within the repleta group is between the hydei subgroup on the one hand and the remaining subgroups on the other, with the fasciola subgroup being the most primitive among the latter forms". Supporting this idea, Morais et al. (1995) proposed the possibility of the repleta group ancestor having inhabited the forests, and, based in composition studies of yeasts, associated to these flies, suggesting that the fasciola subgroup represents the oldest lineage from which the South American species of the repleta group may have evolved. This statement is in agreement to the ecological data mentioned above.

Even though Throckmorton's hypothesis (1962, 1975 and 1982) rests upon morphologic and ecological data, it does not explain the presence of the $3 \mathrm{c}$ inversion in both fasciola and mulleri subgroups, favoring the hypothesis proposed by Wasserman (1962a and b; 1963;1982).

\section{Material and Methods}

We analyzed 26 isofemale strains of seven species in the fasciola subgroup established from specimens collected (Tidon and Sene, 1988; Tidon-Sklorz and Sene, 1992) in different locations (Table 1).

Table 1 - List of strains, collection localities and chromosomal arrangements of seven species of Drosophila in the fasciola subgroup.

\begin{tabular}{|c|c|c|c|c|c|c|c|}
\hline \multirow[t]{2}{*}{ Species } & \multirow[t]{2}{*}{ Strain } & \multirow[t]{2}{*}{ Locality } & \multicolumn{5}{|c|}{ Chromosome standard sequence of PRIMITIVE VII } \\
\hline & & & Xabc & $2 \mathrm{abo}^{2} \mathrm{e}^{3} \mathrm{l}^{3}$ & $3 b$ & 4 & 5 \\
\hline D. carolinae & $\mathrm{J} 16 \mathrm{C} 2$ & Tibagi, PR & + & & $\mathrm{c}$ & $\mathrm{f}^{2 *}, \mathrm{n}^{2 *}$ & + \\
\hline \multirow[t]{12}{*}{ D. coroica } & D88N1 & Sertãozinho, SP & + & + & $\mathrm{c}, \mathrm{p}$ & + & + \\
\hline & D88N19 & “ & + & & $\mathrm{c}, \mathrm{p}$ & + & + \\
\hline & D88N24 & “ & + & + & $\mathrm{c}, \mathrm{p}$ & + & + \\
\hline & D88N27 & “ & + & + & $\mathrm{c}, \mathrm{p}$ & + & + \\
\hline & D88N53 & “ & + & + & $\mathrm{c}, \mathrm{p}$ & + & + \\
\hline & D88N58 & “ & + & + & $\mathrm{c}, \mathrm{p}$ & + & + \\
\hline & D88N60 & “ & + & + & $\mathrm{c}, \mathrm{p}$ & + & + \\
\hline & D88N64 & “ & + & + & $\mathrm{c}, \mathrm{p}$ & + & + \\
\hline & D88N69 & “ & + & + & $\mathrm{c}, \mathrm{p}$ & + & + \\
\hline & D93N3 & Cianorte, PR & + & $\mathrm{v}$ & $\mathrm{c}, \mathrm{p}$ & + & + \\
\hline & D96N6 & São Carlos, SP & + & + & $\mathrm{c}, \mathrm{p}$ & + & + \\
\hline & D96N74 & “ & + & + & $\mathrm{c}, \mathrm{p}$ & + & + \\
\hline \multirow[t]{3}{*}{ D. ellisoni } & D83N5 & Camburi, SP & + & $d^{3} p^{2}$ & $\mathrm{c}$ & + & + \\
\hline & D83N8 & “ & + & $d^{3} p^{2}$ & $\mathrm{c}$ & + & + \\
\hline & D84N11 & “ & + & $d^{3} p^{2}$ & $\mathrm{c}$ & + & + \\
\hline \multirow[t]{4}{*}{ D. fascioloides } & D84N2 & Camburi, SP & + & $d^{3} p^{2}$ & $\mathrm{c}$ & + & + \\
\hline & D86N6 & Nova Friburgo, RJ & + & $d^{3} p^{2}$ & $\mathrm{c}$ & + & + \\
\hline & D86M & “ & + & $d^{3} p^{2}$ & $\mathrm{c}$ & + & + \\
\hline & D86N17 & “ & + & $d^{3} p^{2}$ & $\mathrm{c}$ & + & + \\
\hline
\end{tabular}


Table 1 (cont.)

\begin{tabular}{|c|c|c|c|c|c|c|c|}
\hline \multirow[t]{2}{*}{ Species } & \multirow[t]{2}{*}{ Strain } & \multirow[t]{2}{*}{ Locality } & \multicolumn{5}{|c|}{ Chromosome standard sequence of PRIMITIVE VII } \\
\hline & & & Xabc & $2 \mathrm{abo}^{2} \mathrm{e}^{3} \mathrm{l}^{3}$ & $3 b$ & 4 & 5 \\
\hline D. moju & F34M2 & Panamá, Panama & + & $\mathrm{p}^{2}, \mathrm{r}^{2}, \mathrm{n}^{2}$ & $\mathrm{c}, \mathrm{m}$ & + & $h, \mathrm{i}, \mathrm{j}$ \\
\hline \multirow[t]{4}{*}{ D. onca } & D93N1 & Cianorte, PR & + & + & $\mathrm{c}$ & $\mathrm{f}^{2}$ & + \\
\hline & $\mathrm{H} 61 \mathrm{C} 30$ & Arroio Teixeira, RS & + & + & $\mathrm{c}$ & $\mathrm{f}^{2}$ & + \\
\hline & H61C19 & “ & + & + & $\mathrm{c}$ & $\mathrm{f}^{2}$ & + \\
\hline & $\mathrm{J} 14 \mathrm{C} 2$ & Salto S. Rosa, PR & + & + & $\mathrm{c}$ & $\mathrm{f}^{2}$ & + \\
\hline D. rosinae & $\mathrm{D} 63 \mathrm{C} 1$ & Mucugê, BA & + & + & $\mathrm{c}$ & + & + \\
\hline
\end{tabular}

* - New inversions described in this paper.

Polytene chromosomes from the salivary glands of third instar larvae were prepared by squashing techniques in $2 \%$ lacto-aceto-orcein, fixed in acetic acid and perchloric acid. They were then compared with the maps depicted by Wharton (1942) and Wasserman (1962a).

In order to define the presence of the $3 \mathrm{c}$ inversion, the polytene chromosomes of two species of Drosophila belonging to the mulleri complex of the mulleri subgroup ( $D$. aldrichi and D. mulleri) were also analyzed.

\section{Results}

Of the seven Drosophila species in the fasciola subgroup under study, five came from humid coastal and inland Brazilian forests, one from Panamanian forests and the remaining one from the Caatinga domain (Table 1).

By comparing chromosome 3 of species in the mulleri (D. aldrichi and D. mulleri) and fasciola subgroups, we verified that one of the breakpoints of the $3 \mathrm{c}$ inversion present in the species of the fasciola subgroup is not the same as determined for the $3 \mathrm{c}$ inversion present in the species of the mulleri group. That is, there are two overlapped inversions sharing one breakpoint, and not one single inversion as previously thought. The $3 \mathrm{c}$ inversion was described by Wasserman (1962a), by analyzing species from the fasciola subgroup, as having the $\mathrm{E} 4 \mathrm{a}$ and $\mathrm{G} 1 \mathrm{c}$ breakpoints. However, we observed that the inversion present in the species of the mulleri subgroup differs by one of the two break points: E5b-G1c. Thus, we suggest that this inversion in the mulleri subgroup, as it is still undescribed, should be renamed as $3 \mathrm{u}$. (Figures 1 and 2; Table 1). In addition, two new inversions fixed in chromosome 4 were observed along with the inversions reported in the literature (Table 1; Figure 1). Their breakpoints are shown in Figure 3.

The dozen lineages of D. coroica $(2 \mathrm{n}=12)$ that were analyzed have the previously described sequence $3 p$ (Wasserman, 1962a).

In $D$. ellisoni and $D$. fascioloides $(2 \mathrm{n}=8)$, chromosomes 2 and $4(2-4 F)$ and 3 and $5(3-5 F)$ are fused. These fusions were described earlier by Dobzhansky and Pavan (1943), Wasserman (1962a) and Kuhn et al. (1995), studying metaphase chromosomes. The presence of the $2 \mathrm{p}^{2}$ and

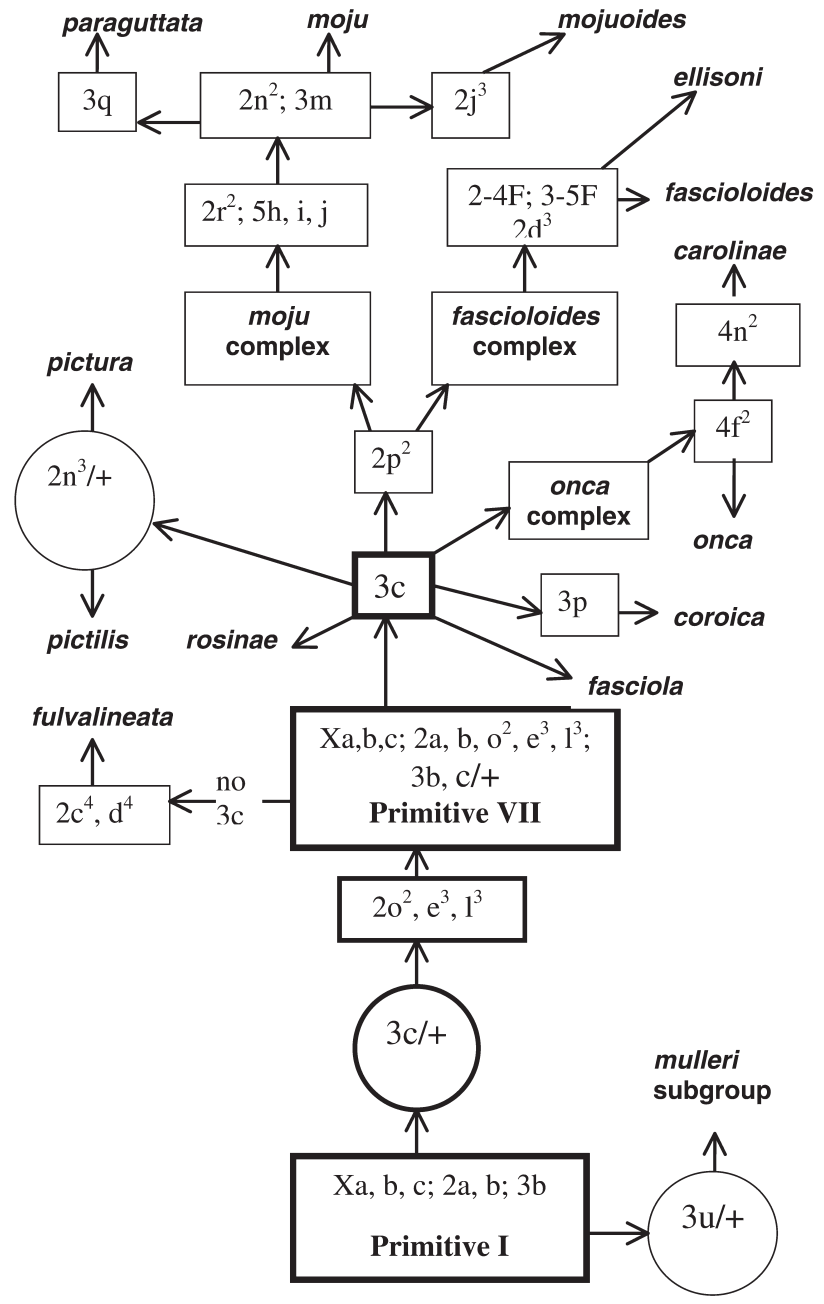

Figure 1 - The diagram illustrates the revised phylogenetic relationships among some species within the fasciola subgroup and between the fasciola subgroup and the mulleri subgroup in the repleta group. as proposed in this study (modified from Wasserman, 1992:522).

$2 \mathrm{~d}^{3}$ inversions was confirmed. The $2 \mathrm{~d}^{3}$ inversion described by Wasserman (1962a) as polymorphic in D. ellisoni (cited as fascioloides) was found to be fixed in our strains.

D. moju, from Panama, has the same sequence previously described by Wasserman (1962a). 


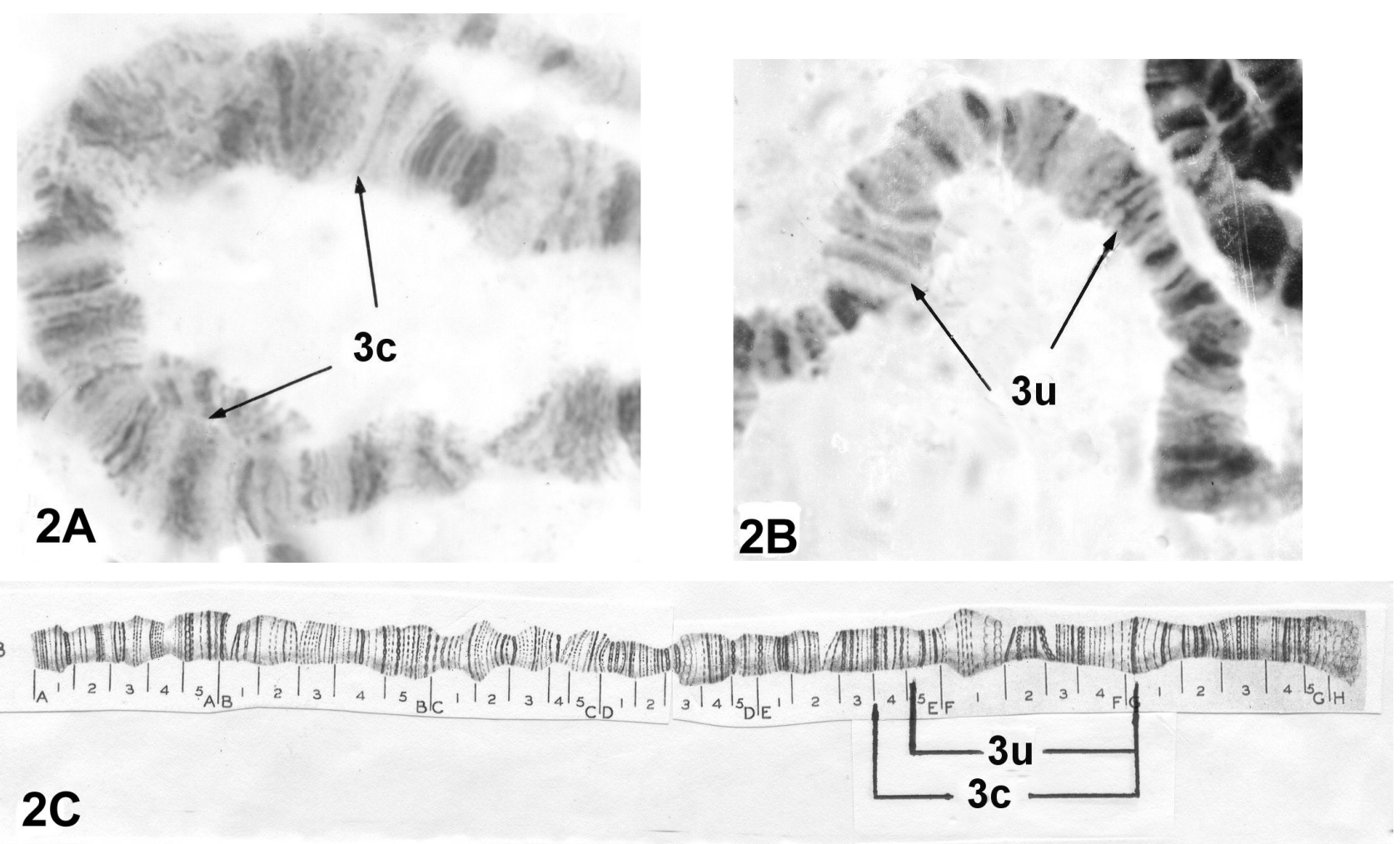

Figure 2 - (A) inversion 3c (D.ellisoni) and (B) inversion 3u (D.aldrichi). The breakpoints are marked in the chromosome map of Drosophila repleta, as depicted by Wharton (1942) (C).

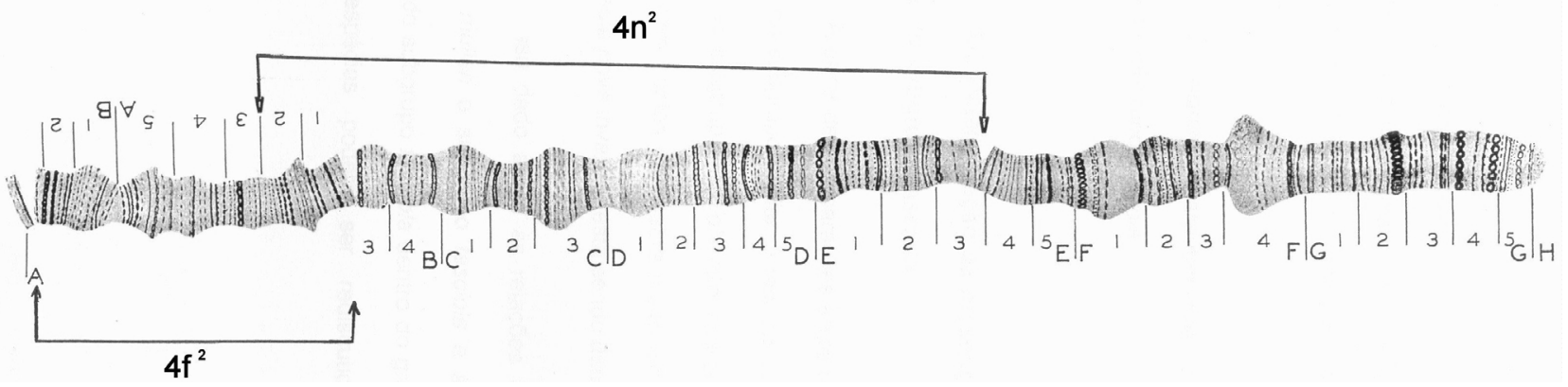

Figure 3 - Breakpoints of inversion $4 \mathrm{f}^{2}$, in Drosophila onca, and inversion $4 \mathrm{n}^{2}$ overlapping inversion $4 \mathrm{f}^{2}$, in D. carolinae, in the chromosome map of Drosophila repleta as depicted by Wharton (1942).

D. onca $(2 \mathrm{n}=12)$ has a fixed inversion on chromosome $4\left(4 \mathrm{f}^{2}\right.$, breakpoints A1c - B3b). D. carolinae $(2 \mathrm{n}=12)$ presents the $4 n^{2}$ inversion (break points A3a - E3i) overlapping the $4 \mathrm{f}^{2}$ arrangement (breakpoints A1c - B 3b) (Figure 3).

D. rosinae $(2 \mathrm{n}=12)$ shows the standard primitive sequence of the fasciola subgroup.

\section{Discussion}

Most of the information obtained in this study is in accordance with the literature (review in Wasserman, 1992). Fixed inversions on chromosome 4 were found in $D$. onca as well as in D. carolinae.
What does not match previous findings is the fact that the $3 \mathrm{c}$ inversion found in fasciola does not have the same $3 \mathrm{c}$ breakpoints as described in the mulleri complex by Wasserman (1962a, b). Accordingly, we propose that the denomination of the inversion present in the species of the mulleri complex be changed from $3 \mathrm{c}$ to $3 \mathrm{u}$. This observation changes the previously proposed phylogenetic relationships among the species in the mulleri and fasciola subgroups as well as the relationships of the species in the fasciola subgroup within the repleta group. The fasciola subgroup becomes derivative of Primitive I in the repleta group and is no longer a derivative of the mulleri complex, as proposed by Wasserman (63) (Figure1). The present hy- 
pothesis was required for the subgroup fasciola to be considered ancestral of the repleta group with a forest origin, as proposed by Throckmorton $(1975,1982)$ and "supported" by morphological and ecological data (Pipkin, 1965; Pipkin et al., 1966; Sene et al., 1977; Pereira et al., 1983; Morais et al., 1995). This new phylogenetic hypothesis, based on chromosomal inversions, offers a better perspective to understanding the relationships within the subgroup to be inferred from other markers as in Costa and Sene (2002).

Furthermore, based on cytological data, we propose two new species complexes within the fasciola subgroup: the fascioloides complex, comprising $D$. ellisoni and $D$. fasciloides which share one inversion $\left(2 \mathrm{~d}^{3}\right)$, two centric fusions (2-4F and $3-5 \mathrm{~F})$, and a great karyotype similarity regarding the X chromosomes (Kuhn et al., 1995); and the onca complex, comprising D. carolinae and D. onca, which share one inversion $\left(4 \mathrm{f}^{2}\right)$ in addition to the similarity in the morphology of their aedeagi as shown by Vilela (1983). The species $D$. rosinae directly derives from Primitive VII, the hypothetic ancestral sequence to the fasciola subgroup (Figure1), after fixation of the $3 \mathrm{c}$ inversion.

\section{Acknowledgments}

The authors wish to thank Prof Marwin Wasserman for the time NM Diniz spent in his laboratory, CR Vilela for providing the stock of $D$. moju, MH Manfrin for a critical reading of the manuscript, MAR Alves for assistance in obtaining the chromosome preparations, and PR Epifânio for assistance in the maintenance of stocks. Financial support from CAPES, CNPq, FAPESP, FINEP and USP made this study possible.

\section{References}

Bächli G and Vilela CR (2002) Six new species of Drosophila (Diptera, Drosophilidae) from Parque Nacional Henri Pittier, Venezuela. Mitt Schweiz Ent Ges 75:223-243.

Costa CTA and Sene FM (2002) Characterization of courtship sounds of species of the subgroup fasciola (Diptera, Drosophilidae, Drosophila repleta group): Interspecific and interpopulational analyses. Braz J Biol 62:573-583.

Dobzhansky Th and Pavan C (1943) Studies on Brazilian species of Drosophila. Boletins da Faculdade de Filosofia, Ciências e Letras da Universidade de São Paulo 36 (Biologia Geral 4):7-72.

Kuhn GCS, Diniz NM, Alves MAR and Sene FM (1995) Constituição cariotípica de espécies do subgrupo fasciola do grupo repleta do gênero Drosophila. Rev Brasil Genet 18(3-s):282.

Morais PB, Rosa CA, Hagler AN and Hagler LCM (1995) Yeast communities as descriptor of habitat use by the Drosophila fasciola subgroup (repleta group) in Atlantic rain forests. Oecologia 104:45-51.

Patterson JT and Wheeler MR (1942). Description of new species of the subgenera Hirtodrosophila and Drosophila. Univ Texas Publ 4213:67-109.

Pavan C (1959) Relações entre populações naturais de Drosophila e o meio ambiente. Boletins da Faculdade de Filosofia,
Ciências e Letras da Universidade de São Paulo 221 (Biologia Geral 11):7-81.

Pereira MAQR, Vilela CR and Sene FM (1983) Notes on breeding and feeding sites of some species of the repleta group of the genus Drosophila (Diptera, Drosophilidae). Cien Cult 35:1313-1319.

Pipkin SB (1965) The influence of adult and larval food habits on population size of neotropical ground-feeding Drosophila. AmMidlNat 74:1-27.

Pipkin SB, Rodriguez RL and Leon J (1966) Plant host specificity among flower-feeding Neotropical Drosophila (Diptera, Drosophilidae). Amer Natur 100:135-156.

Rafael V and Arcos G (1989) Subgrupo inca, un nuevo subgrupo del grupo repleta, con descripción de Drosophila huancavilcae n. sp. (Diptera, Drosophilidae). Evol Biol 3:233-243.

Sene FM, Paganelli CHM, Pedroso LC, Garcia E and Palombo (1977) Local de criação de Drosophila onca. Cien Cult 29(7 supl.): 716.

Sene FM, Val FC, Vilela CR and Pereira MAQR (1980) Preliminary data on the geographical distribution of Drosophila species within morphoclimatic domains of Brazil. Pap Avulsos de Zool (São Paulo) 33:315-326.

Sturtevant AH (1942) The classification of the genus Drosophila with description of nine new species. Univ Texas Publ 4213:5-51.

Throckmorton LH (1962) The Problem of Phylogeny in the Genus Drosophila. Univ Texas Publ 6205:207-343.

Throckmorton LH (1975) The phylogeny, ecology and geography of Drosophila. In: King RC (ed) Handbook of Genetics v 3. Plenum Press, New York, pp 421-469.

Throckmorton LH (1982) Pathways of evolution in the genus Drosophila and the founding of the repleta group. In: Barker JSF and Starmer WT (eds) Ecological Genetics and Evolution - The Cactus-Yeast Drosophila Model System. Academic Press, Sydney, pp 33-47.

Tidon R and Sene FM (1988) A trap that retains and keeps Drosophila alive. DIS 67:89.

Tidon-Sklorz R and Sene FM (1992) Vertical and temporal distribution of Drosophila (Diptera, Drosophilidae) species in wooded area in the state of São Paulo, Brazil. Rev Bras Biol 52:311-317.

Tidon-Sklorz R and Sene FM (1995a) Evolution of the buzzatii cluster (Drosophila repleta species group) in the Northeastern South America. Evol Biol 8/9:71-85.

Tidon-Sklorz R and Sene FM (1995b) Drosophila seriema n.sp: New Member of the Drosophila serido (Diptera, Drosophilidae) Superspecies Taxon Ann Entomol Soc Am 88:139-142.

Tidon-Sklorz R and Sene FM (1995c) Fauna of Drosophila (Diptera, Drosophilidae) in the northern area of the "Cadeia do Espinhaço", states of Minas Gerais and Bahia, Brazil: Biogeographical and ecological aspects. Iheringia, Ser Zool 78:85-94.

Tidon-Sklorz R and Sene FM (2001) Two New Species of the Drosophila serido Sibling Set (Diptera, Drosophilidae). Iheringia, Ser Zool 90:141-146.

Tidon-Sklorz R, Vilela CR, Sene FM and Pereira MAQR (1994) The genus Drosophila (Diptera, Drosophilidae) in the Serra do Cipó. Rev Bras entomol 38:627-637. 
Vilela CR (1983) A revision of the Drosophila repleta species group (Diptera, Drosophilidae). Rev Bras entomol 27:1-114.

Vilela CR, Pereira MAQR and Sene FM (1983) Preliminary data on the geographical distribution of Drosophila species within morphoclimatic domains of Brazil: II.The repleta group. Cien Cult 35:66-70.

Vilela CR and Bächli G (1990) Taxonomic studies on neotropical species of seven genera of Drosophilidae (Diptera). Mitt Schweiz Ent Ges 63(suppl.):1-332.

Wasserman M (1954) Cytological studies of the repleta group. Univ Texas Publs 5422:130-152.

Wasserman M (1960) Cytological and phylogenetic relationships in the repleta group of the genus Drosophila Proc Nat Acad Sci 46:842-859.

Wasserman M (1962a) Cytological studies of the repleta group of genus Drosophila: VI. The fasciola subgroup. Univ Texas Publs 6205:119-134.
Wasserman M (1962b) Cytological studies of the repleta group of genus Drosophila: V. The mulleri subgroup. Univ Texas Publs 6205:86-117.

Wasserman M (1963) Cytology and phylogeny of Drosophila. Amer Natur 97:333-352.

Wasserman M (1982) Evolution of the repleta group. In: Ashburner M, Carson HL and Thompson JN (eds) The Genetic and Biology of Drosophila. v. 3b. Academic Press, London, pp 61-139.

Wasserman M (1992) Cytological evolution of the Drosophila repleta species group. In: Krimbas CB and Powell J.R. (eds) Drosophila Inversion Polymorphism. CRC Press, Boca Raton, USA, pp 455-552.

Wharton LT (1942) Analysis of the repleta group of Drosophila. Univ Texas Publs 4228:23-52.

Associate Editor: Angela Maria Vianna-Morgante 